maintains that acceptance of some prima facie desirable practice is wrong because it would logically commit us to accepting a series of other, undesirable practices. The psychological form maintains that if certain practices are once accepted, other undesirable practices will in fact come to be accepted. As becomes clear later in the book, these two forms of argument can often be combined: loose concepts, it is claimed, can and will be stretched under pressure of a prevailing climate of opinion to cover circumstances not originally envisaged by those who accepted the first steps.

The discussion of Nazi policy which follows examines what is often thought to be the paradigm case of sliding down the slippery slope, in order to see whether we can learn from this case. Here the main points tend to be somewhat obscured amid the detail of argument, but Lamb does claim that, like the Nazis, if for different reasons, we are nowadays starting to say that some lives are not worth living, and that this is the beginning of a slope.

Lamb himself espouses a principle that all lives are worth living (in themselves, not just to their livers - a sort of secular equivalent of the notion of the sanctity of human life). Sometimes he seems to say that all suicide and euthanasia is wrong because of this principle. At other times he invokes slippery-slope considerations, such as the inherent vagueness of the concepts of rationality, voluntariness, autonomy and so on, to argue against legalising euthanasia. His arguments are very ingenious, but I found them unconvincing - particularly as rationality and autonomy seem to underpin the right to refuse treatment, which Lamb does wish to uphold. There is much detailed argument about euthanasia, including a brief treatment of cost-benefit arguments. In comparison, the treatment of in vitro fertilisation, genetic engineering and abortion is rather cursory. An important and interesting topic, that of the respect due to human tissue, is introduced but not sufficiently developed, and I remain unclear why Lamb seems happier about abortion than about euthanasia.

I suspect that this book is really about euthanasia rather than slipperyslope arguments. Lamb wishes to argue against legalising euthanasia for both value-of-life and slippery-slope reasons, though the latter are not always set out in a way which clearly displays their nature. He argues that while some cases of euthanasia may be morally acceptable, there is no safe way of codifying this fact. The book is closely argued, thought-provoking and in general well written (though the Oxford English Dictionary does say that the word 'beneficient', often used, is an erroneous form). Anyone interested in euthanasia would benefit from reading this book, although they might not be converted.

ELIZABETH TELFER, Department of Philosophy, University of Glasgow.

\section{Sickness and health}

Colin Douglas, London, Heinemann, 1991, 523 pages, £14.99

This major novel, the title of which gives no indication of content, takes the reader behind the visible façade of respectable medical life. It is a vivid story of two generations of doctors and patients, with all their desires, ambitions, disappointments and heartaches. Written in Douglas's typical style, which combines wit, satire, cynicism, insight and realism, it captures the life experiences of people who represent various epochs in the history of the National Health Service.

In an unusual and most effective way, the author sets the scene with the funeral, in 1979, of a well respected doctor, who met an untimely and mysterious death. He then goes back in time to 1949, the year of the implementation of the NHS in Scotland, where the whole novel is acted out. Colourful vignettes depict and highlight important epochs. With a non-descriptive title, the four section headings are important: 1 . We are making a new world; 2 . Victories of science; 3 . The long surprise; and 4. The health you can afford. They depict the early visions of the health service, the anguish of the medical rat race, the prejudices against female medics and some of the life/death decisions taken overtly or covertly. Ethical issues are cleverly woven into the fabric and, thus, the book earns itself a review in this journal.

As a reviewer who worked in the NHS from its inception, I can appreciate the realism of the novel. It is uncannily possible to identify with the doctors, medical students, nurses and patient who act out their fictitious roles. Thus the book is valuable in bringing to life some of the many non- fictional historical accounts of this era in the NHS.

On the negative side, I missed an index and some sort of an author's.. introduction, setting out his aims and $\overrightarrow{\vec{F}}$ direction. It took me quite a while to get my bearings. In parts, I found the style and language somewhat crude and lacking in sensitivity, but maybe this reflects the author's perception of $\varrho$ the world which he so vividly presents to his readers. The novel deserves to be read; its subtleties are intriguing.

LISBETH HOCKEY, Honorary Reader in Nursing Research, $\overline{(})$

Queen Margaret College, Edimburgh

\section{Challenges in caring: explorations in nursing and ethics}

\author{
J M Brown, A C Kitson, and T J \\ McKnight, Chapman and Hall,
}

London, 1992, 215 pages, £13.95

Increasing awareness of profession responsibilities has caused membes. of the caring professions to look ev more closely at the nature and underlying principles of their practice: nursing is a case in point. Increased professionalisation and access to $\varrho$ higher education (there are now some $\overline{\bar{\sigma}}$ 20 nursing degree courses in the 3 United Kingdom) has raised awareness of the need to form a view, and 0 sometimes adopt a stance, on issues which past generations of nurses may well have left to others, most notably, the medical or legal professions; ethics is a case in point. The regulatory bodies for nursing, midwifery and health visiting have, over recent years, suggested professional/ethical principles around which nursing can be conceptualised and from which prac- 을 titioners can derive support. Without being over-prescriptive, such guide- $\Omega$ lines provide focus and promote dis- $N$ cussion of ethical issues faced daily by N్ many nurses.

Challenges in Caring: Explorations in Nursing and Ethics sets out to exam- 을 ine a range of topics, most of which $\mathbb{E}$ occasion public and professional $\stackrel{+}{+}$ debate. Written by two philosophers $T$ and a nurse, the book attempts to discuss ethical principles in the light $\overparen{D}$ of real-life ethical dilemmas often $\frac{\mathbb{D}}{\mathbb{Q}}$ faced by nurses. This two-pronged approach is exemplified by the open- 
ing line: 'Am I going to die, nurse?' It is developed well in early chapters but, curiously, the nursing aspects then tend to fade away.

Faced with such a book, it is always tempting for a reviewer to ponder the choice and balance of topics: why some are included and others left out. Also, when attempts are made to build bridges between academic disciplines and the social realities of nursing (a graveyard for many aspiring authors) balance and relevance are all-important if the reader's attention is to be held. Overall, this reviewer appreciated the choice of topics but found it curious that pressing and timely issues such as contraception, population explosion, mental health, and substance abuse are not considered, whereas abortion and reproductive technology receive extensive coverage: perhaps the latter are viewed as more directly healthrelated but many nurses might question this assumption.

The first two chapters, on moral thinking and moral deliberation introduce basic ideas. Chapters three to eight are highly relevant to nurses, with many important aspects of practice discussed. However, the book is patchy in its coverage: chapters eight to twelve covering abortion, reproductive technology, death and dying, and respecting life, depart from the earlier style of combining ethics with nurse/patient situations: it is as if the effort required to achieve such a rapprochment ran out of steam. The text remains interesting as a straight debate on medical ethics but nurses may feel an opportunity was lost. Professional matters reappear in the the final two chapters. There are some useful appendices.

This book would make a useful text for students of nursing ethics and for stimulating debate on ethical aspects of care. Nurse teachers could draw on it selectively for a range of preregistration courses.

PROFESSOR JACK HAYWARD, Nursing Research Unit, King's College, London.

\section{The nature of moral thinking}

Francis Snare, London and New York, Routledge, 1992, 187 pages, $£ 30.00$ hc, $£ 9.99 \mathrm{pb}$
The preface to this book says 'The Nature of Moral Thinking will satisfy the intellectually curious student, providing a solid and fair discussion of the classical philosophical questions about our moral thinking, surveying the main types of meta-ethical and normative ethical theories ...' Whether that is a fair assessment depends in part on what is meant by 'student'.

If it means someone studying moral philosophy in an institution of higher education, exposed to lectures, tutorials, classes, and other reading on the subject, then this book - which is based on the author's first-year lectures at Sydney University - could well prove a valuable handbook. Although it does not engage with live moral issues such as may arise in health care (the preface explains: 'Discussions of applied ethics are certain to be circumscribed unless underlying philosophical assumptions about deeper, more general issues are treated'), it touches on most of the topics with which moral philosophy has traditionally been concerned. I particularly enjoyed Snare's extended discussions of Plato's Euthyphro problem and of psychological egoism, and he is good at picking out varieties of relativism and subjectivism and shooting down sloppy-minded arguments that tend to get propagated in these areas.

On the debit side, it is a pity that, of the standard meta-ethical theories, he gives scant attention to intuitionism. Second, I think it was an error of judgement to include a chapter on the relativist theory of truth suggested in Plato's Theaetetus. It is based on lectures by David Armstrong, a colleague of Snare's, and stands as a selfcontained set-piece, impressive in itself but insufficiently connected to the book's official subject-matter of moral philosophy. Third, Snare makes little reference to the debates of the past decade about what has come to be called 'moral realism'. Perhaps these debates are too sophisticated for an introductory book; perhaps they merely offer new glosses on old positions; still, the omission seems a lack. Fourth, Snare is occasionally too terse and unforthcoming: there are remarks which read a bit like a lecturer's asides to a knowing audience (for example pages 48 and 173), and some ideas or theories (for example the prisoners' dilemma on page 170 , and non-natural properties on page 166) get mentions bereft of elucidation. Nevertheless, I shall be strongly recommending this book to my own first-year students.

The book cannot be so readily recommended to that other kind of student, the interested general reader uncushioned by an environment of institutionalised teaching of the subject. In particular, the occasional terseness may present difficulties for such a reader. What illumination would she or he get, for instance, from the following criticism (I quote it in its entirety) of the existentialist idea of an existential, self-creating choice of values: 'This is a bit mysterious' (page 157). Such undeveloped passages may, however, be a consequence of a sad fact: the author was still working on the manuscript when he died of cancer at the age of 47 , and revisions were completed and the book seen through the press by colleagues.

P F BROWNSEY Department of Philosophy, Glasgow University.

\section{Moral luck in medical ethics and practical politics}

\author{
Donna Dickenson, Aldershot, \\ Avebury, 1991,153 pages, $£ 30.00$
}

Problems of moral luck arise primarily from our tendencies, on the one hand, to hold agents responsible to a degree which depends at least partly on the outcomes of their decisions or actions (the killer drunken driver is more culpable than the non-killer), and, on the other, not to hold agents responsible for what is beyond their control.

The debate over moral luck in recent times was set in motion by a famous exchange between Bernard Williams and Thomas Nagel in 1976. In this book, Donna Dickenson takes that debate, which we might say has been carried on primarily at the level of theoretical ethics, and uses it to shed light on some practical issues in medical and political ethics. As she hopes, her practical discussions also help to elucidate certain theoretical matters.

The first three chapters outline the debate between Williams and Nagel, and investigate moral luck in Kantian and consequentialist ethics. Dickenson argues that Martha Nussbaum's critique of Kant in her book The Fragility of Goodness is unjustified: Kant does make room for moral risk 